\title{
Increase in markers of airway inflammation after ozone exposure can be observed also in stable treated asthmatics with minimal functional response to ozone
}

\author{
Barbara Vagaggini, Maria Laura E Bartoli, Silvana Cianchetti, Francesco Costa, Elena Bacci, Federico L Dente, \\ Antonella Di Franco, Laura Malagrinò, Pierluigi Paggiaro*
}

\begin{abstract}
Background: The discrepancy between functional and inflammatory airway response to ozone has been reported in normal subjects, but few data are available for stable asthmatics regularly treated with inhaled corticosteroids.

Methods: Twenty-three well controlled, regularly treated, mild-to-moderate asthmatic patients underwent two sequential randomised exposures to either filtered air or ozone $(0.3$ ppm for 2 hours) in a challenge chamber. Pulmonary function (PF) was monitored, and patients with FEV1 decrease greater than 10\% from pre-challenge value were considered as responders. Immediately after each exposure, exhaled breath condensate (EBC) was collected to measure malondialdehyde (MDA). Six hours after each exposure, PF and EBC collection were repeated, and sputum was induced to measure inflammatory cell counts and soluble mediators (IL-8 and neutrophil elastase). The response to ozone was also evaluated according to the presence of polymorphism in oxidative stress related NQO1 and GSTM1 genes.
\end{abstract}

Results: After ozone exposure, sputum neutrophils significantly increased in responders $(n=8)$, but not in nonresponders $(n=15)$. Other markers of neutrophil activation in sputum supernatant and MDA in EBC significantly increased in all patients, but only in nonresponders the increase was significant. In nonresponders, sputum eosinophils also significantly increased after ozone. There was a positive correlation between ozoneinduced FEV1 fall and increase in sputum neutrophils. No difference in functional or inflammatory response to Ozone was observed between subjects with or without the combination of NQO1wt- GSTM1null genotypes.

Conclusions: Markers of neutrophilic inflammation and oxidative stress increase also in asthmatic subjects not responding to ozone. A greater functional response to ozone is associated with greater neutrophil airway recruitment in asthmatic subjects.

\section{Background}

Ozone is a potent oxidant known to induce a variety of respiratory effects, including cough, increased airway reactivity, decrease in lung function and neutrophilic airway inflammation [1]. Recent evidence supports a role for environmental chronic exposure to ozone in the development of asthma and in triggering asthma attacks $[2,3]$. Ozone exposure imposes an oxidative burden on the lung both by directly oxidizing biomolecules, thereby

\footnotetext{
* Correspondence: Ipaggiaro@dcap.med.unipi.it

Cardio-Thoracic and Vascular Department, University of Pisa, Pisa, Italy
}

generating reactive oxygen species (ROS), and by inducing inflammatory mediator production and release, with activation of inflammatory cells and further release of ROS [4]; this process causes acute and chronic airway damage, which results in bronchoconstriction and bronchial hyperresponsiveness [5].

Many studies have reported an increase in markers of neutrophilic activation in induced sputum or in bronchoalveolar lavage (BAL) after ozone exposure in healthy ad asthmatic subjects [6,7], as well as an increase in markers of oxidative stress in lung tissue and BAL fluid 
of animals exposed to high ozone concentrations [8]. There is, however, considerable interindividual variability in the magnitude of pulmonary response, both in terms of functional and inflammatory reaction to ozone exposure, with a large proportion of subjects showing no significant change in airway calibre after controlled experimental ozone exposure in laboratory [9]. No specific determinants of poor functional response to ozone have been demonstrated, apart from age and levels of exposure $[10,11]$. Most experimental studies in humans have reported no correlation between functional response and severity of inflammatory response measured in induced sputum or bronchoalveolar lavage fluid [12-14]. In particular, very few data have been reported in asthmatic subjects.

In humans, increased levels of malondialdehyde and 8isoprostane have been measured in breath condensate after O3 exposure $[15,16]$.

Polymorphism of two oxidative stress related enzymes, Glutathione-S-Transferase M1 (GSTM1) and NAD(P)H: quinone oxidoreductase (NQO1), has been associated with an increased susceptibility to ozone exposure injury. There are studies showing that the deleted form of Glutathione-S-Transferase M1 enzyme (GSTM1 null), resulting in a complete lack of its enzymatic function, associated with the pro187 form of $\mathrm{NAD}(\mathrm{P}) \mathrm{H}$ :quinone oxidoreductase (NQO1) enzyme, induces greater acute airway and inflammatory responses to ozone $[17,18]$.

The aim of our study was to evaluate the effects of ozone exposure on functional and inflammatory airway responses in 23 mild-to-moderate, stable asthmatic subjects, regularly treated with inhaled corticosteroids. We and other authors have demonstrated that inhaled or oral corticosteroids can blunt neutrophilic airway inflammatory response to ozone in asthmatics [19-21], but have little effect on airway calibre. Therefore, we would like to verify whether, in asthmatic subjects regularly treated with inhaled corticosteroids, a dissociation between functional and inflammatory airway response to ozone can be observed.

\section{Subjects and methods Subjects}

We selected 23 nonsmoking, mild-to-moderate stable asthmatic subjects, regularly treated with inhaled corticosteroids (median daily dose: $500 \mu \mathrm{g}$ of BDP-equivalent, range: 200-1000), associated with long-acting beta2-agonists in 19 out of 23 subjects, all aged under 50 years. Asthma severity and level of control were assessed according to International Guidelines [22]. All subjects were in stable phase of disease and had had no upper respiratory tract infection or acute asthma exacerbation in the last 4 weeks. Asthma treatment was withdrawn 24 hrs before each exposure. Main characteristics of examined subjects are reported in Table 1.

\section{Study design}

On two different days, at least 2 weeks apart, all subjects were randomly exposed to either ozone $(0.3 \mathrm{ppm})$ or filtered air for 2 hours in a challenge chamber, while excercising on a cycloergometer. Before and after each exposure, they underwent pulmonary function test (PFT), collected exhaled breath condensate (EBC) and measured nitric oxide levels in exhaled air (eNO). Six hours after the end of the exposure, PFT, EBC collection, eNO measurements were repeated, and hypertonic saline (HS)-induced sputum was collected.

The study protocol was approved by the local University Ethic Committe, and an informed consent was obtained by each patient before entering in the study.

Subjects were divided in responders and nonresponders according to their responsiveness to ozone, corrected by the changes in airway calibre after exposure to air. Airway responsiveness to ozone was defined as the difference between $\mathrm{FEV}_{1}$ values $(\mathrm{L})$ measured after $\mathrm{O}_{3}$ and after air exposure $\left(\triangle \mathrm{FEV}_{1}\right.$ O3-Air $)$, according to the following formula:

$$
\Delta \mathrm{FEV}_{1 \text { O3-Air }}=\frac{\mathrm{FEV}_{1} \text { pre }_{3}(\mathrm{~L})-\mathrm{FEV}_{1} \text { post }_{3}(\mathrm{~L})}{\mathrm{FEV}_{1} \text { pre } \mathrm{O}_{3}(\mathrm{~L})} \times 100-\frac{\mathrm{FEV}_{1} \text { pre air }(\mathrm{L})-\mathrm{FEV}_{1} \text { post air }(\mathrm{L})}{\mathrm{FEV}_{1} \text { pre air }(\mathrm{L})} \times 100
$$

Subjects with $\triangle \mathrm{FEV}_{1}$ O3-Air greater than $10 \%$ were considered as "responders" [12].

Table 1 Characteristics of the asthmatic subjects examined

\begin{tabular}{lccc}
\hline & All subjects & Responders & Nonresponders \\
\hline Number & 23 & 8 & 15 \\
\hline Age, yrs (M \pm SD) & $32.6 \pm 10.8$ & $31.1 \pm 13.2$ & $33.4 \pm 9.8$ \\
\hline Sex (Male/Female) & $13 / 10$ & $6 / 2$ & $7 / 8$ \\
\hline Atopy (yes/no) & $17 / 6$ & $5 / 3$ & $12 / 3$ \\
\hline Smoking habit (yes/ex/no) & $0 / 5 / 18$ & $0 / 2 / 6$ & $0 / 3 / 12$ \\
\hline FEV1, \% predicted (M \pm SD) & $96.9 \pm 12.0$ & $93.4 \pm 15.9$ & $98.8 \pm 9.4$ \\
\hline PD20FEV1 meth, mg (GM) & 0.263 & 0.366 & 0.218 \\
\hline ICS, $\mu$ g/d (median, range) & $500(200-1000)$ & $500(250-1000)$ & $500(200-1000)$ \\
\hline
\end{tabular}

FEV1:Forced expiratory volume in one second ; M \pm SD: mean \pm standard deviation; GM: geometric mean. PD20FEV1 meth: cumulative dose of methacoline provoking a 20\% decrease in FEV1 from baseline value; ICS: Inhaled corticosteroids. 
Venous blood was taken before the first exposure, to evaluate the genotypic combination of $\mathrm{NAD}(\mathrm{P}) \mathrm{H}$ :quinone oxidoreductase (NQO1) and Glutathione-S-Transferase M1 (GSTM1) enzymes. Functional and inflammatory airway responses of subjects bearing both NQO1wt and GSTM1null genotypes were compared with those of the other genotypic combinations.

\section{Challenge chamber}

All subjects were exposed to ozone for $120 \mathrm{~min}$ in a 9$\mathrm{m}^{3}$ static challenge chamber made of glass and aluminium [19], while exercising on a stationary cycloergometer at work load predetermined to produce a ventilation rate of $25 \mathrm{~L} / \mathrm{min} / \mathrm{m}^{2}$ of body surface area for twenty min every hour. Ozone was generated by a corona discharge $\mathrm{O}_{3}$-generator (Rancon Instruments $\mathrm{SpA}$, Milano, Italy) connected to a cylinder of purified air. Ozone output into the chamber was $0.5 \mathrm{~L} / \mathrm{min}$. An $\mathrm{O}_{3}$ analyser (Photometric $\mathrm{O}_{3}$ Analyser 400, Rancon Instruments SpA, Milano, Italy) connected to the chamber by a tubing circuit, continuously monitored gas concentration. Mean ozone concentration was maintained at about $0.3 \mathrm{ppm}$ throughout the exposure. A fan in the chamber ensured adequate gas mixing and circulation.

\section{Sputum induction and processing}

Hypertonic saline solution $(\mathrm{NaCl} 4.5 \%)$ was nebulized with an ultrasonic nebulizer $(2.8 \mathrm{ml} / \mathrm{min}$ output; Sirius, Technomed, Firenze, Italy) and inhaled for three 5-minute periods, for up to $15 \mathrm{~min}$. Every $5 \mathrm{~min}$ after the start of nebulization, patients were asked to carefully rinse their mouth and throat in order to discard saliva and to try to cough sputum into a clean container; FEV1 was then measured. Nebulization was stopped after 15 min or when FEV1 fell by $20 \%$ or more from baseline values.

Sputum samples were processed within $2 \mathrm{~h}$ from collection, and more viscid and denser portions were selected and processed as previously described [23]. Briefly, samples were homogenized by adding $0.1 \%$ dithiothreitol in a shaking bath at $37^{\circ} \mathrm{C}$ for $15 \mathrm{~min}$ and centrifuged to separate cells from supernatant. Supernatant was stored at $-80^{\circ} \mathrm{C}$ for further analysis. The cell pellet was resuspended in phosphate-buffered saline for viability test and total cell count; aliquots were cytocentrifuged (Cytospin; Shandon Scientific, Sewickley, PA, USA) to prepare slides for differential cell counts. At least 300 inflammatory cells were counted. Macrophage, lymphocyte, neutrophil, eosinophil values were expressed as percent of total inflammatory cells.

Slides with cell viability $<50 \%$ or with an amount of squamous cells such that 300 inflammatory cells could not be counted were considered inadequate and discarded. Our reproducibility for sputum inflammatory cell counts was previously assessed and excluding lymphocytes (RI: 0.23), was considered as satisfactory: RI was 0.90 for macrophages, 0.88 for neutrophils, 0.82 for eosinophils [24].

\section{Exhaled breath condensate (EBC) collection}

EBC was collected by cooling exhaled air with a specifically designed condenser (Ecoscreen, Jaeger, Wurzburg, Germany). Subjects breathed tidally for 15 min through a two-way non-rebreathing valve in order to prevent inspiratory and espiratory air mixing and saliva trapping [25]. The condensate thus obtained was immediately stored at $-30^{\circ} \mathrm{C}$ for further analysis.

\section{Exhaled Nitric Oxide (eNO) measurement}

$\mathrm{NO}$ was measured in exhaled air using a Nitric Oxide Analyzer (Sievers NOA 280, Boulder, CO, USA). Under visual feedback, patients performed a single slow exhalation $(30-45 \mathrm{sec})$ from total lung capacity through a resistance, keeping a constant expiratory flow of about $50 \mathrm{~L} /$ min; eNO concentration at mouth level was recorded throughout expiration. At least three acceptable manoeuvres with eNO variability lower than $10 \%$ were obtained, and the mean value was considered.

\section{Biochemical analysis}

\section{Cytokines and neutrophilic biomarkers}

Sputum supernatant IL-8 levels were measured with a commercially available enzyme immunoassay (Euroclone, Milano, Italy) according to manufacturer's recommended protocol. The detection limit of the assay was $0.0625 \mathrm{ng} / \mathrm{ml}$. The percentage of recovery, evaluated in 10 different samples, was $89.4 \%$. Intra- and inter-assay coefficients of variation were $4.7 \%$ and $7.5 \%$, respectively [26].

Sputum Neutrophilic Elastase activity (NE) in induced sputum supernatant was measured spectrophotometrically using the synthetic substrate methoxysuccinyl-alaala-pro-val-paranitroanilide (MeOSAAPVpNa) (Sigma ALDRICH Company Ltd. Poole, Dorset, UK). Activity was measured by assessing the change in absorbance at $410 \mathrm{~nm}$ on a microplate reader, and quantified by extrapolation from a standard curve of pure NE. The detection limit of the method was $6 \mathrm{ng} / \mathrm{ml}$. Intra- and interassay coefficients of variation were $5.6 \%$ and $12 \%$ respectively. NE recovery, measured in 28 samples, was greater than $80 \%$ [26].

\section{Oxidative stress biomarkers}

Malondialdehyde (MDA) concentrations were measured in sputum supernatant and EBC samples according to the method described by Larstad et al [27]. Briefly, samples were derivatised with tiobarbituric acid and then measured by means of High Performance Liquid Chromatography with fluorescence detector (HPLC; Binary HPLC pump 1525 and 2475 multi $\lambda$ fluorescence detector, Waters, Milano, Italy), using excitation and emission wavelenghts of 532 and 553nm respectively. Our detection limit was $0.006 \mu \mathrm{m} / \mathrm{L}$, the intra- and inter-assay 
reproducibility were 0.9 and $10.4 \%$ respectively and the recovery $96 \%$.

\section{Genotypic characterization}

GSTM1 and NQO1 genotypes were characterized by molecular biology techniques, using genomic DNA extracted with Nucleon BACC2 (Amersham International plc, Little Chalfont, Buckinghamshire, UK) from peripheral blood after buffy-coat enrichment, according to the procedures described elsewhere [17].

\section{Statistical analysis}

Functional data are expressed as mean \pm standard deviation, and compared between groups using unpaired Student's t-test. Comparison between repeated measurements in the same group was performed using ANOVA test. Inflammatory markers are expressed as median and range, and compared between groups using Mann-Whitney U test. The correlation between FEV response to ozone and $\mathrm{O}_{3}$-air changes in inflammatory markers has been evaluated using Spearman's rank correlation coefficient. A p value lower than 0.05 has been considered as significant.

\section{Results}

Eight (34.7\%) of the 23 subjects studied were defined as responders to ozone. No difference was found between responders and nonresponders for the main baseline characteristics (Table 1 ). Six subjects $(26 \%)$ had the NQO1wt e GSTM1null genotypic combination.

\section{Functional response}

Mean values of $\mathrm{FEV}_{1}, \mathrm{FVC}$ and VC at different timepoints during exposures to air or ozone, divided into responders and nonresponders, are reported in Table 2. No difference in baseline values (expressed either as

Table 2 FVC, VC and FEV1 measured at different timepoints before and after exposure to air or ozone, in responders and nonresponders

\begin{tabular}{lcccc}
\hline & \multicolumn{2}{c}{ Responders $(\mathbf{n}=\mathbf{8})$} & \multicolumn{2}{c}{ Nonresponders $(\mathbf{n}=\mathbf{1 5})$} \\
\hline FVC bas & $4.65 \pm 0.78$ & $4.70 \pm 0.63$ & $4.69 \pm 0,97$ & $4.56 \pm 1.00$ \\
\hline FVC 2h & $4.69 \pm 0.75$ & $4.38 \pm 0.79 \S \#$ & $4.63 \pm 0.93$ & $4.52 \pm 0.93 \S \#$ \\
\hline FVC 6h & $4.69 \pm 0.84$ & $4.61 \pm 0.79$ & $4.67 \pm 0.99$ & $4.56 \pm 1.00$ \\
\hline \multicolumn{5}{c}{} \\
\hline VC bas & $4.60 \pm 0.79$ & $4.69 \pm 0.70$ & $4.60 \pm 0.99$ & $4.55 \pm 0.99$ \\
\hline VC 2h & $4.67 \pm 0.75$ & $4.43 \pm 0.80 \S \#$ & $4.67 \pm 0.96$ & $4.49 \pm 0.89$ \\
\hline VC 6h & $4.64 \pm 0.83$ & $4.56 \pm 0.77$ & $4.72 \pm 0.99$ & $4.54 \pm 1.04 \S$ \\
\hline & & & & \\
\hline FEV1 bas & $3.59 \pm 0.76$ & $3.73 \pm 0.62$ & $3.55 \pm 0.86$ & $3.41 \pm 0.88$ \\
\hline FEV1 2h & $3.79 \pm 0.72$ & $3.40 \pm 0.57 \S \#$ & $3.60 \pm 0.88$ & $3.52 \pm 0.81 \S$ \\
\hline FEV1 6h & $3.80 \pm 0.75$ & $3.59 \pm 0.58$ & $3.69 \pm 0,96$ & $3.50 \pm 0.87 \S$ \\
\hline
\end{tabular}

FEV1:Forced expiratory volume in one second; FVC: Forced vital capacity; VC: Vital capacity. \# $p<0.05$ from baseline values; $\S: p<0.05$ from air at the same time point. Data are expressed as mean \pm SD. percentage or as absolute value) was found between ozone and air challenges in both groups. As expected, in addition to $\mathrm{FEV}_{1}$ decrease, responders also showed significant decrease in $\mathrm{FVC}$ and $\mathrm{VC}$ at the end of ozone exposure in comparison with pre-ozone exposure values, with complete recovery by $6 \mathrm{~h}$ after exposure. However, nonresponders showed mild but significant reduction in $\mathrm{FEV}_{1}, \mathrm{FVC}$ and $\mathrm{VC}$ at the end of ozone exposure only when compared with after air exposure.

There was no difference in functional response to ozone challenge between subjects bearing NQO1wt and GSTM1null genotypes and subjects bearing different genotypic combinations $(\triangle \mathrm{FEV} 1 \%$ O3-Air: $3.75 \pm 5.83$ vs $1.54 \pm 13.26 \%$, ns).

\section{Inflammatory response}

Inflammatory findings of the study subjects, grouped in responders and nonresponders, are reported in Table 3. Two subjects did not collect adequate sputum samples or breath condensate in at least one occasion, and they were thus excluded from analysis.

After ozone exposure, sputum neutrophils significantly increased in responders, but not in nonresponders. Sputum IL-8 and NE did not show any significant increase in responders $(\mathrm{p}=0.13$ and $\mathrm{p}=0.15$ respectively), while in nonresponders IL-8 and NE increased after ozone exposure, although the increase in NE was only close to the statistical significance.

When the difference between sputum neutrophil percentage after ozone and after air for each subject $(\Delta \mathrm{N}$ $\%)$ was considered, a significantly higher value was observed in responders than in nonresponders (15.2 $[-1.3,64.5]$ vs $0.15[-21,2,52.5] \%, \mathrm{p}<0.05)$.

Sputum eosinophils (both in absolute and percent value) after ozone exposure were significantly higher than after air exposure only in nonresponders.

When all subjects were considered together, MDA levels in EBC were significantly higher immediately after ozone exposure, in comparison with air, but not 6 hours later (Figure 1). When subjects were grouped according to their functional response to ozone, MDA concentrations in EBC increased from baseline in both groups, but the difference was significant only in nonresponders (Figure 2).

Nitric oxide (eNO) levels in exhaled air were above normal value $(20 \mathrm{ppb})$ in 13 out of 23 asthmatic subjects (mean values: $33.7 \pm 29.9 \mathrm{ppb}$ and $34.1 \pm 29.7 \mathrm{ppb}$ before air and ozone exposure respectively) and did not significantly change immediately and 6 hours after either air or ozone exposures.

No difference in the inflammatory response to ozone exposure was found between subjects bearing NQO1wt and GSTM1null genotypes and subjects bearing different genotypic combinations. 
Table 3 Inflammatory cells and soluble mediators in induced sputum after either air or ozone exposure, in subjects grouped according to functional response to ozone exposure

\begin{tabular}{|c|c|c|c|c|}
\hline & \multicolumn{2}{|c|}{ Responders $(n=8)$} & \multicolumn{2}{|c|}{ Nonresponders $(n=13)$} \\
\hline & Air & Ozone & Air & Ozone \\
\hline Infamm. cells/ml $\left(10^{6}\right)$ & $2.6(1.5-5.7)$ & $3.6(1.2-10.8)$ & $2.1(0.2-6.8)$ & $3.1(0.7-14.0)$ \\
\hline Macrophages/ml $\left(10^{6}\right)$ & $0.9(0.3-2.2)$ & $1.4(0.3-3.2)$ & $0.8(0.1-2.5)$ & $0.9(0.4-10)$ \\
\hline Lymphocytes/ml $\left(10^{6}\right)$ & $0.03(0-0.3)$ & $0.09(0-0.4)$ & $0.02(0-0.1)$ & $0.02(0-0.1)$ \\
\hline Neutrophils/ml $\left(10^{6}\right)$ & $0.7(0.2-2.0)$ & $1.7(0.5-9.2) \S$ & $0.6(0-6.3)$ & $0.8(0.1-7.0)$ \\
\hline Eosinophils/ml $\left(10^{6}\right)$ & $0.09(1-1.9)$ & $0.02(0-0.6)$ & $0.02(0-1.7)$ & $0.4(0-1.6) \# \S$ \\
\hline Macrophages (\%) & $40.4(8-89)$ & $34.3(8-77)$ & $51.1(6-85)$ & $48.2(2-75)$ \\
\hline Lymphocytes (\%) & $1.5(1-6)$ & $1.4(0-14)$ & $0.6(0-5)$ & $0.8(0-5)$ \\
\hline Neutrophils (\%) & $28.2(8-79)$ & $55.4(23-90) \S$ & $41.0(0-93)$ & $30.9(6-98)$ \\
\hline Eosinophils (\%) & $2.8(0-55)$ & $0.2(0-11)$ & $0.3(0-63)$ & $11.6(0-45) \# \S$ \\
\hline $\mathrm{NE}(\mathrm{ng} / \mathrm{mL})$ & $0.7(0-6)$ & $2.1(0-9)$ & $1.2(0-5)$ & $1.5(0-6.5)$ \\
\hline NE rec.(\%) & $42(1-61)$ & $59(34-83)$ & $41(9-62)$ & $60(33-78) \wedge$ \\
\hline IL-8 (ng/mL) & $22.9(10-44)$ & $36.3(3-62)$ & $11.8(6-72)$ & $26.3(3-94) \S$ \\
\hline
\end{tabular}

Inflamm.: inflammatory; NE: neutrophil elastase; NE rec: NE recovery; IL-8: interleukin 8. Data are expressed as median (range). $§: p<0.05$ from air exposure; $\wedge p=$ 0.056 from air exposure; \#:p $<0.05$ from responders.

\section{Relationship between functional and biological data}

Considering all the subjects together, a significant correlation was found between $\triangle \mathrm{FEV} 1 \%_{\mathrm{O} 3 \text {-Air }}$ and ozone-air difference sputum neutrophil percentages $(\Delta$ N\%) (Figure 3). No significant correlation was observed between changes in FEV1 and the ozone-air difference of the other inflammatory markers studied.

No correlation was observed between O3-air changes in MDA immediately after exposure and changes in sputum neutrophils 6 hours after exposure.

After ozone exposure, a positive correlation was found between neutrophil counts (cells $/ \mathrm{ml})$ and NE ( $\mathrm{p}=0.01$, rho $=0.6)$ and IL-8 levels $(p=0.03$, rho $=0.6)$ in induced sputum.

\section{Discussion}

The main result of this study was that some asthmatic subjects defined as "nonresponders" showed however an increase in airway markers of neutrophilic inflammation and oxidative stress, thus suggesting that they are nonetheless sensitive to the effect of ozone. In nonresponders, eosinophils (but not neutrophils) and IL-8 in sputum and MDA in exhaled breath condensate increased after ozone exposure, despite clinically

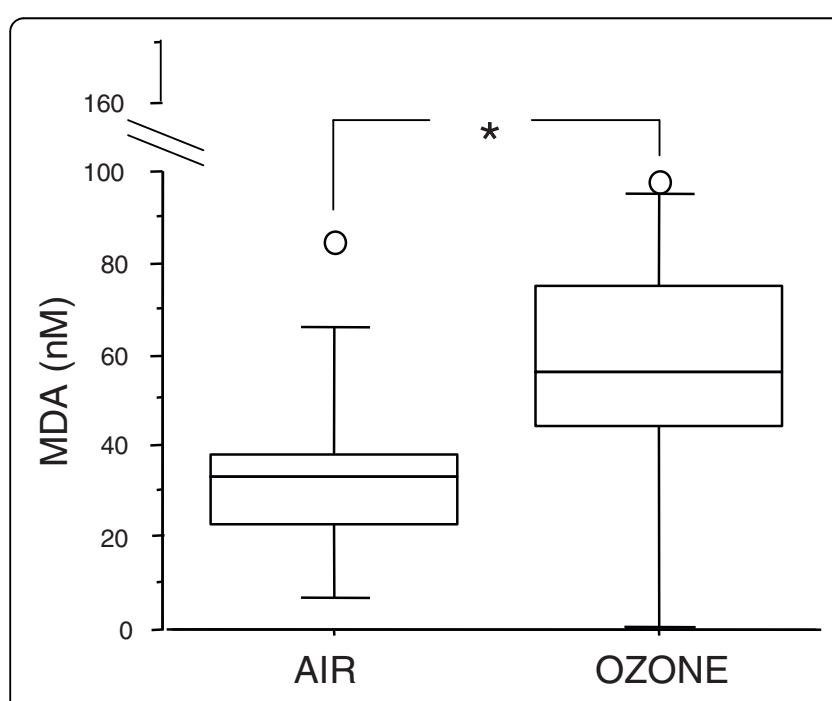

Post exposure

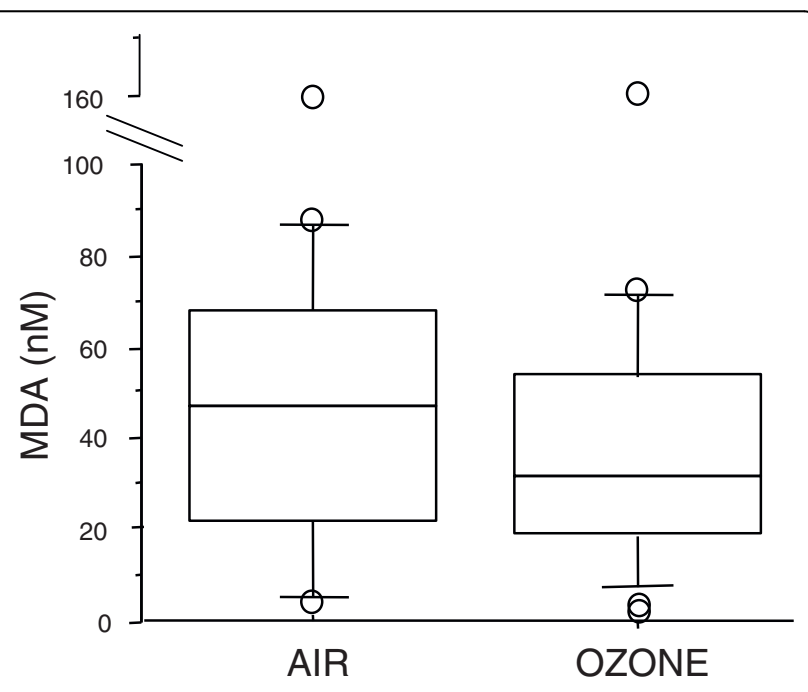

6h post exposure

Figure 1 MDA in EBC immediately and 6 hours after ozone/air exposure in all subjects (responders plus nonresponders); ${ }^{*} p<0,05$. 


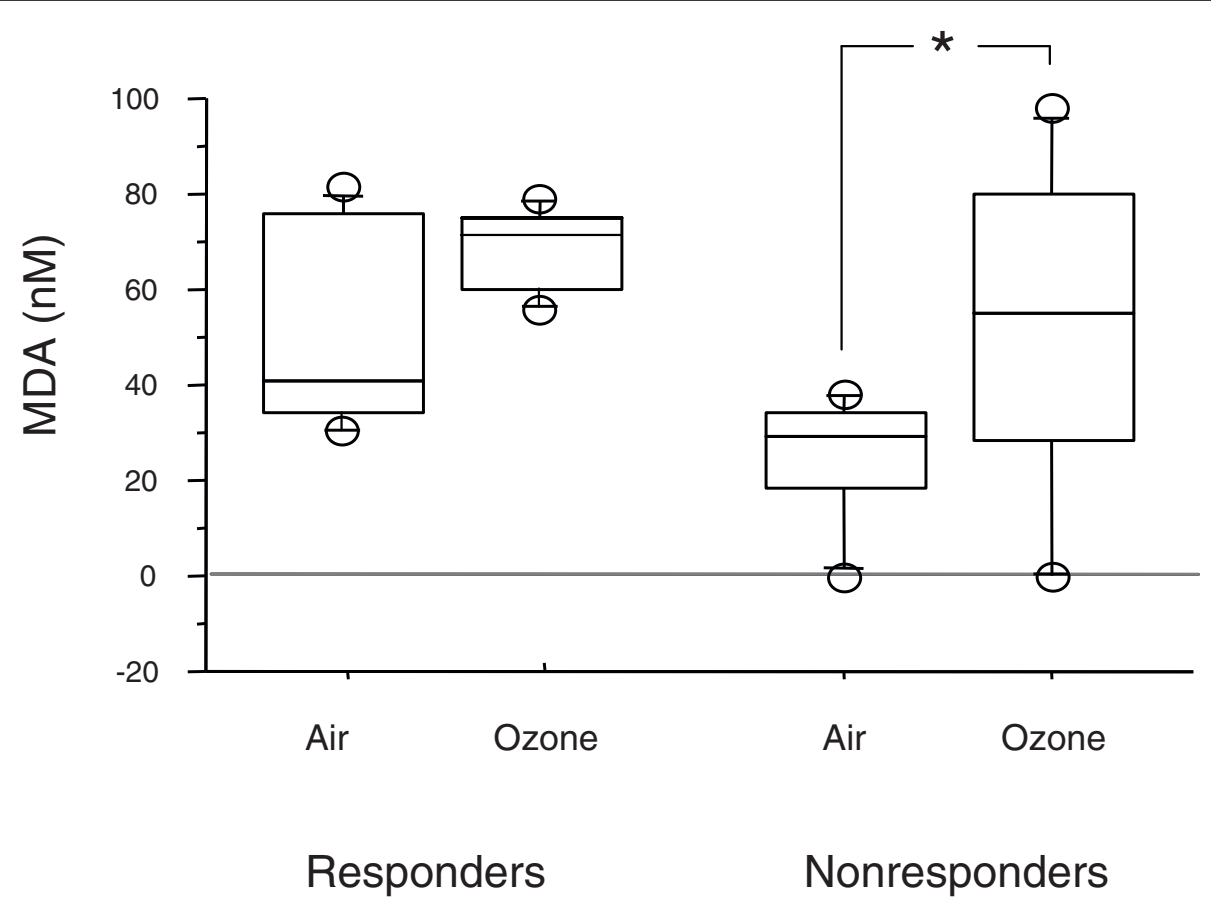

Figure 2 MDA in EBC immediately after ozone or air exposure in responders and nonresponders. ${ }^{*} p<0,05$.

nonsignificant changes in pulmonary function. The inverse relationship between sputum neutrophils and FEV1 values after exposure was significant only when responders and nonresponders were taken all together.

Only a small subgroup of the 23 asthmatic subjects studied had a functional airway response to ozone, which was associated with airway neutrophil recruitment. This fact may be due to regular pharmacologic treatment with inhaled corticosteroids, which may have blunted the severity of restrictive ventilatory impairment in most patients studied. The data reported in literature about functional and inflammatory airway response to ozone in asthmatic subjects are controversial: while some studies showed a greater inflammatory response in asthmatics compared to normal subjects $[28,29]$, these data have not been reproduced by other authors [30], although all the patients studied were free from treatment with inhaled corticosteroids. In previous studies,

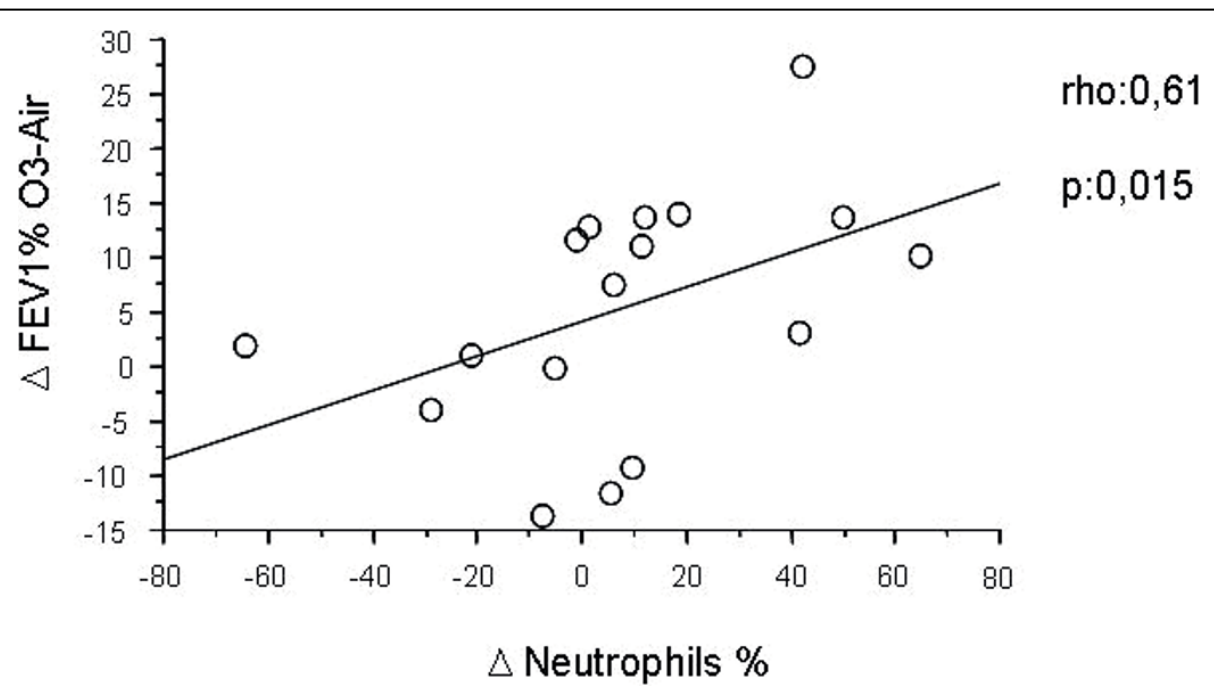

Figure 3 Correlation between FEV1 fall after ozone (corrected by air) and changes in sputum neutrophils ( $\Delta$ Neutrophils\%) in all subjects (responders plus nonresponders) (Spearman Rank correlation test). 
we demonstrated that asthmatic patients with persistent asthma, regularly treated with inhaled corticosteroids, had a lower functional response to ozone [6], and that short-period pre-treatment with inhaled or oral corticosteroids had some effect on the airway response to ozone $[19,20]$.

In subjects defined as "nonresponders" to ozone, there was however a mild decrease in FEV1, FVC and VC at different time points after ozone exposure and of no clinical relevance; sputum neutrophils, however, did not significantly increase. Despite the lack of a relevant functional and inflammatory response, ozone exposure still induced a significant immediate increase in MDA in exhaled breath condensate, and a later increase in neutrophilic soluble markers in induced sputum in these subjects. This delayed acute inflammatory response to ozone may predispose asthmatic subjects to greater sensitivity to other specific or non specific triggers of acute bronchoconstriction. Indeed, a relationship between peaks of environmental ozone concentrations and asthma symptoms or Peak Expiratory Flow decrease in asthmatics has been reported, with a time lag of 2-3 days $[31,32]$, even in asthmatic subjects on regular pharmacologic treatment [33]. These observations suggest that regularly treated, well-controlled asthmatic subjects are not completely protected from an increase in airway inflammation and oxidative stress, and this may predispose to subsequent asthma deterioration.

The increase in MDA was observed immediately after ozone exposure but not 6 hours later, when neutrophilic recruitment in the airways was observed. Although no significant correlation was found between the immediate increase in MDA and the late increase in sputum neutrophilc after ozone exposure, we may hypothesize that the oxidative stress induced by ozone in the airway epithelium may be one of several mechanisms of recruitment and activation of neutrophils in the airways.

When both responders and nonresponders were considered together, a significant correlation between changes in FEV1 and changes in sputum neutrophils was observed. This relationship has never been previously shown by other authors, and in general no correlations between functional and biochemical changes induced by ozone have been reported [12-14]. However, all studies have been performed in healthy volunteers with high airway reactivity to ozone, whereas our study included asthmatic subjects with very mild functional response to ozone and a blunted ozone-induced airway inflammation, probably due to the long-term regular treatment with inhaled corticosteroids.

The increase in sputum eosinophils in nonresponders found in the present study is an original observation, and requires to be confirmed by further investigations. Other authors have demonstrated an increase in sputum or BAL eosinophils or ECP levels, or in urinary EPX in asthmatic or healthy subjects exposed to ozone, but the relationship with functional response was not reported $[34,35]$. In a previous experience, we observed that when ozone exposure is performed 24 hours after an allergen challenge that has induced a late response, sputum eosinophil percentages are increased in comparison to the exposure to air, suggesting that ozone may amplify allergen-induced eosinophil airway inflammation [36].

We studied patients with well controlled asthma, after a short-term withdrawal (24 hours) of the regular treatment with ICS, associated with LABA in the majority of them. This short duration of the treatment withdrawal before each exposure allows to avoid a direct effect of ICS and mainly of LABA on the airway response, but it does not exclude a possible interference from the longterm ICS use. It is well known that the effect of ICS on airway cells may persist up to some weeks after the withdrawal. Because a long-term withdrawal of ICS was not possible in our patients, most of them affected by moderate asthma, we preferred to withdraw both ICS and LABA treatment 24 hours before each exposure, in order to minimize and standardize the possible interference of asthma treatment. This strategy has been used previously by other authors [29].

We found no difference between subjects bearing NQO1wt e GSTM1null genotypic combination and those with other genotypic combinations, as regards both functional and biological response to ozone exposure. The few works published on this topic, mainly evaluating ozone-induced functional changes, are controversial. Our results are in agreement with two studies performed either after acute or chronic exposure to ozone $[15,37]$, which found no difference in lung function between different genotypic combinations. The small number of subjects bearing the NQO1wt and GSTM1null genotypic combination $(\mathrm{n}=6)$ and the different time points chosen in our study might explain the lack of concordance with other studies reporting an ozone-induced increase in oxidative stress markers in this group of subjects $[15,17]$.

In conclusion, the increase in some markers of airway inflammation and/or oxidative stress can be observed also in asthmatic subjects who do not functionally respond to ozone. The low rate of functional response can be due to the blunting effect of the previous regular pharmacological treatment in this category of well controlled asthmatics.

\section{Abbreviations}

FEV1: Forced Expiratory Volume in one Second; FVC: Forced Vital Capacity; VC: Vital Capacity; PF: Pulmonary Function; PFT Pulmonary Function Test; PD20FEV1 meth: cumulative dose of methacoline producing a 20\% decrease 
in FEV1 from baseline value; ICS: Inhaled Corticosteroids; EBC: Exhaled Breath Condensate; BAL: Bronchoalveolar Lavage; ROS: Reactive Oxigen Species; eNO: exhaled Nitric Oxide; HS: Hypertonic Solution; DTT: Dithiothreitol; PBS: Phosphate Buffer Solution; NE: Neutrophilic Elastase; MDA: Malondialdehyde; IL-8: Interleukin-8; GSTM1: Glutathione-S-Transferase; NQO1: NAD(P)H:quinone Oxidoreductase; ECP: Eosinophil Cationic Protein; EPX: Eosinophil Peroxidase; LABA: Long Acting Beta Agonists.

\section{Acknowledgements}

We thank Mrs. Mariella De Santis and Mrs Elisa Masino for performing functional evaluations and sputum induction. We also thank Dr. Massimo Corradi from the University of Parma (Italy) for performing the genotypic characterization of the patients. The study was supported by a grant of the Italian Ministry of University and of Scientific and Technologic Research (MURST), \# prot 2003060145_002.

\section{Authors' contributions}

PLP and BV designed the study; ADF, EB, BV, FC and LM supervised clinical and functional evaluations; MLB and SC did the laboratory analysis; FLD the statistical analysis. BV, PLP and MLB wrote the manuscript, and all the authors read and approved the final version of the manuscript.

\section{Competing interests}

PLP has received in the last 5 years funds from AstraZeneca, Abbott, Boehringer Ingelheim, Chiesi Pharmaceutical, GlaxoSmithKline, and MerckSharp\&Dohme, Novartis, Nycomed and Valeas for teaching and research activities.

None of the other authors has any competing interest to declare.

Received: 30 December 2008

Accepted: 19 January 2010 Published: 19 January 2010

\section{References}

1. Bernstein JA, Alexis N, Barnes C, Bernstein IL, Bernstein JA, Nel A, Peden D, Diaz-Sanchez D, Tarlo SM, Williams PB: Health effects of air pollution. $J$ Allergy Clin Immunol 2004, 114:1116-23.

2. McConnell R, Berhane K, Gilliand F, London SJ, Islam T, Gauderman WJ, Avol E, Margolis HG, Peters JM: Asthma in exercising children exposed to ozone: a cohort study. Lancet 2002, 359:386-391.

3. Committe of the Environmental and Occupational Health Assembly of the American Toracic Society: Health effect of outdoor air pollution. State of the art. Am J Respir Crit Care Med 1996, 153:3-50.

4. Koren HS, Devlin RB, Graham DE, Mann R, McGee MP, Horstmann DH, et al: Ozone induced inflammation in the lower airways of human subjects. Am Rev Resp Dis 1989, 139:407-415.

5. Peden DB: Air pollution in asthma: effect of pollutants on airway inflammation. Ann Allergy Asthma Immunol 2001, 87:12-17.

6. Vagaggini $B$, Carnevali S, Macchioni P, Taccola M, Fornai E, Bacci E, Bartoli ML, Cianchetti S, Dente FL, Di Franco A, Giannini D, Paggiaro PL: Airway inflammatory response to ozone in subjects with different asthma severity. Eur Respir J 1999, 13:274-80.

7. Jorres RA, Holz O, Zachgo W, Timm P, Koschyk S, Müller B, Grimminger F, Seeger W, Kelly FJ, Dunster C, Frischer T, Lubec G, Waschewski M, Niendorf A, Magnussen $H$ : The effect of repeated ozone exposures on inflammatory markers in bronchoalveolar lavage fluid and mucosal biopsies. Am J Respir Crit Care Med 2000, 161:1855-61.

8. Jang AS, Choi IS, Yang SY, Kim YG, Lee JH, Park SW, Park CS: Antioxidant responsiveness in BALB/C mice exposed to ozone. Respiration 2005, 72:7984.

9. Frampton MW, Morrow PE, Torres A, Cox C, Voter KZ, Utell MJ: Ozone responsiveness in smokers and nonsmokers. Am J Respir Crit Care Med 1997, 155:116-121

10. McDonnell WF, Muller KE, Bromberg PA, Shy CM: Predictors of individual differences in acute response to ozone exposure. Am Rev Respir Dis 1993, 147:818-825

11. McDonnell WF, Stewart PW, Andreoni S, Seal E jr, Kehrl HR, Horstman DH, Folinsbee LJ, Smith MV: Prediction of ozone-induced FEV1 changes. Effects of concentration, duration and ventilation. Am J Respir Crit Care Med 1997, 156:715-722.
12. Balmes JR, Chen LL, Scannell C, Tager I, Christian D, Hearne PQ, Kelly T, Aris RM: Ozone-induced decrements in FEV1 and FVC do not correlate with measures of inflammation. Am J Respir Crit Care Med 1996, 153:904-9.

13. Holz O, Jörres RA, Timm P, Mücke M, Richter K, Koschyk S, Magnussen H: Ozone-induced airway inflammatory changes differ between individuals and are reproducible. Am J Respir Crit Care Med 1999, 159:776-84.

14. Blomberg A, Mudway IS, Nordenhall C, Hedenstrom H, Kelly FJ, Frew AJ, Holgate ST, Sandstrom T: Ozone-induced lung function decrements do not correlate with early airway inflammatory or antioxidant responses. Eur Respir J 1999, 13:1418-1428.

15. Corradi M, Alinovi R, Goldoni M, Vettori M, Folesani G, Mozzoni P, Cavazzini S, Bergamaschi E, Rossi L, Mutti A: Biomarkers of oxidative stress after controlled human exposure to ozone. Tox Lett 2002, 134:219-225.

16. Montuschi P, Nightingale JA, Kharitonov SA, Barnes PJ: Ozone-induced increase in exhaled 8-isoprostane in healthy subjects is resistant to inhaled budesonide. Free Radic Biol Med 2002, 15(33):1403-8,

17. Bergamaschi E, De Palma G, Mozzoni P, Vanni S, Vettori MV, Broeckaert F, Bernard A, Mutti A: Polymorphism of quinone-metabolizing enzymes and susceptibility to ozone-induce acute effect. Am J Resp Crit Care Med 2001, 163:1426-31.

18. David GL, Romieu I, Sienra-Monge JJ, Collins WJ, Ramirez-Aguilar M, del RioNavarro BE, Reyes-Ruiz NI, Morris RW, Marzec JM, London SJ: Nicotinamide adenine dinucleotide (phosphate) reduced:quinone oxidoreductase and glutathione S-transferase M1 polymorphisms and childhood asthma. Am J Respir Crit Care Med 2003, 168:1199-204.

19. Vagaggini B, Taccola M, Conti I, Carnevali S, Cianchetti S, Bartoli ML, Bacci E, Dente FL, Di Franco A, Giannini D, Paggiaro PL: Budesonide reduces neutrophilic but not functional airway response to ozone in mild asthmatics. Am J Respir Crit Care Med 2001, 164:2172-2176.

20. Vagaggini B, Cianchetti S, Bartoli M, Ricci M, Bacci E, Dente FL, Di Franco A, Paggiaro PL: Prednisone blunts airway neutrophilic inflammatory response due to ozone exposure in asthmatic subjects. Respiration 2007, 74:61-8.

21. Holz O, Tal-Singer R, Kanniess F, Simpson KJ, Gibson A, Vessey RS, Janicki S, Magnussen $\mathrm{H}$, Jörres RA, Richter $\mathrm{K}$ : Validation of the human ozone challenge model as a tool for assessing anti-inflammatory drugs in early development. J Clin Pharmacol 2005, 45:498-503.

22. Global Initiative for Asthma, National Institute of Health, National Heart Lung and Blood Institute: Global strategy for asthma management and prevention. NHLBINHO workshop report no. 02-3659 Bethesda, NHLBI 2003.

23. Bacci E, Cianchetti S, Paggiaro PL, Carnevali S, Bancalari L, Dente FL, Di Franco A, Giannini D, Vagaggini B, Giuntini C: Comparison between hypertonic and isotonic saline-induced sputum in the evaluation of airway inflammation in subjects with moderate asthma. Clin Exp Allergy 1996, 26:1395-400

24. Bacci E, Cianchetti S, Carnevali S, Bartoli ML, Dente FL, Di Franco A, Giannini D, Vagaggini B, Paggiaro PL: Induced sputum is a reproducible method to assess airway inflammation in asthma. Mediators Inflamm 2002, 11:293-8.

25. Horváth I, Hunt J, Barnes PJ: Exhaled breath condensate: methodological recommendations and unresolved questions. Eur Respir J 2005, 26:523-48.

26. Cianchetti S, Bacci E, Bartoli ML, Ruocco L, Pavia T, Dente FL, Di Franco A, Vagaggini B, Paggiaro P: Can hypertonic saline inhalation influence preformed chemokine and mediator release in induced sputum of chronic obstructive pulmonary disease patients? Comparison with isotonic saline. Clin Exp Allergy 2007, 37:1819-26.

27. Larstad M, Ljungkvist G, Olin AC, Toren K: Determination of malondialdehyde in breath condensate by high-performance liquid chromatography with fluorescence detection. J Chromatogr B Analyt Technol Biomed Life Sci 2002, 5(766):107-14.

28. Scannell C, Chen L, Aris BM, Tager I, Christian D, Ferrando R, Welch B, Kelly T, Balmes JR: Greater ozone-induced inflammatory responses in subjects with asthma. Am J Respir Crit care Med 1996, 154:24-29.

29. Basha MA, Gross KB, Gwizdala CJ, Haidar AH, Popovich J Jr: Bronchoalveolar lavage neutrophilia in asthmatic and healthy volunteers after controlled exposure to ozone and filtered purified air. Chest 1994, 106:1757-65.

30. Stenfors N, Pourazar J, Blomberg A, Krishna MT, Mudway I, Helleday R, Kelly FJ, Frew AJ, Sandstrom T: Effect of ozone on bronchial mucosal inflammation in asthmatic and healthy subjects. Respir Med 2002, 96:352358. 
31. Romieu I, Meneses F, Ruiz S, Huerta J, Sienra JJ, White M, Etzel R, Hernandez M: Effects of intermittent ozone exposure on peak expiratory flow and respiratory symptoms among asthmatic children in Mexico City. Arch Environ Health 1997, 52:368-76.

32. Romieu I, Sienra-Monge JJ, Ramírez-Aguilar M, Téllez-Rojo MM, MorenoMacías H, Reyes-Ruiz NI, del Río-Navarro BE, Ruiz-Navarro MX, Hatch G, Slade R, Hernández-Avila M: Antioxidant supplementation and lung functions among children with astrhma exposed to high levels of air pollutants. Am J Respir Crit Care Med 2002, 166:703-709.

33. Gent JF, Triche EW, Holford TR, Belanger K, Bracken MB, Beckett WS, Leaderer BP: Association of low-level ozone and fine particles with respiratory symptoms in children with asthma. JAMA 2003, 290:18591867.

34. Hiltermann JT, Lapperre TS, van Bree L, Steerenberg PA, Brahim JJ, Sont JK, Sterk PJ, Hiemstra PS, Stolk J: Ozone-induced inflammation assessed in sputum and bronchial lavage fluid from asthmatics: a new non invasive tool in epidemiologic studies on air pollution and asthma. Free Radic Biol Med 1999, 27:1448-54.

35. Frischer T, Studnicka M, Halmerbauer G, Horak F jr, Gartner C, Tauber E, Koller DV: Ambient ozone exposure is associated with eosinophil activation in healthy children. Clin Exp Allergy 2001, 31:1213-9.

36. Vagaggini B, Taccola M, Cianchetti S, Carnevali S, Bartoli ML, Bacci E, Dente FL, Di Franco A, Giannini D, Paggiaro PL: Ozone exposure increases eosinophilic airway response induced by previous allergen challenge. Am J Respir Crit Care Med 2002, 15(166):1073-7.

37. Chen C, Arjomandi M, Tager IB, Holland N, Balmes JR: Effects of antioxidant enzyme polymorphisms on ozone-induced lung function changes. Eur Respir J 2007, 30:677-83.

doi:10.1186/1465-9921-11-5

Cite this article as: Vagaggini et al:: Increase in markers of airway inflammation after ozone exposure can be observed also in stable treated asthmatics with minimal functional response to ozone. Respiratory Research 2010 11:5.

Publish with Bio Med Central and every scientist can read your work free of charge

"BioMed Central will be the most significant development for disseminating the results of biomedical research in our lifetime. "

Sir Paul Nurse, Cancer Research UK

Your research papers will be:

- available free of charge to the entire biomedical community

- peer reviewed and published immediately upon acceptance

- cited in PubMed and archived on PubMed Central

- yours - you keep the copyright 